\title{
Application of Computer Guidance System on Physical Demonstration and Exploration
}

\author{
Bing Wang ${ }^{1, \text { a }}$ \\ ${ }^{1}$ Maritime Department of Henan Communication Vocational Technology College, Zhengzhou, \\ Henan, China, 450005 \\ a email
}

Keywords: Computer Guidance System, Physical Demonstration, Exploration, Application

\begin{abstract}
With the continuous development and progress of computer technology, physical education has been greatly affected by computer Guidance systems in physics teaching can improve students 'interest in learning, improve students' attention. It begins with a simple analysis of the computer system operating environment Guidance, Guidance analysis computer system function modules, Guidance focuses on computer system in physics teaching, hoping to provide a reference for physical education.
\end{abstract}

\section{Introduction}

The purpose of physical education is to enable students to understand and grasp the laws of physics, students thinking ability and practical ability, how to cultivate the students' thinking ability, creativity and practical ability, so that students really feel the physical world, to stimulate enthusiasm for learning, improve the quality of teaching, the most effective solution would be to combine teaching content and physics experiments. The traditional demonstration experiment in physics teaching did not play its due role, so students generally reflect the physical class abstract, and difficult too difficult to learn. And by allowing students to participate in college physics experiment demonstration and guidance teachers, guiding the way, the students will correctly understand the physical concepts University, Law and Law play a positive role, and increase students' interest in exploration of physical phenomena, and further improve the physical theory courses teaching effect.

Currently, many high school to improve teaching effectiveness, have set up a physical demonstration and exploration practice base, set up a demonstration room mechanics, electrical work of the Office and other areas, to cover most of the pilot projects in the demonstration room is equipped with a computer system Guidance for students demonstrate work, video, etc., in a more intuitive physics presented in the form of knowledge, teaching effectiveness is improved, the following analysis of the main computer system Guidance physical demonstration and exploration applications.

\section{The Status and Role of Demonstration Experiments in Physics Teaching}

Constructivist Learning Environment as four elements namely situation, cooperation, conversation and construct meaning in physics teaching, teaching for the construction of demonstration experiments can create a suitable learning environment. With the continuous deepening of the implementation of the new curriculum, textbooks on physics experiments have become increasingly demanding, requires more emphasis on the experimental ability of students to explore knowledge. Demonstration Experiment on the syllabus requirements than ever, the new curriculum standards for the number of physical demonstration experiment, quality and other requirements have greatly improved, in order to better play to make demonstration experiment inquiry teaching functions, more conducive students' knowledge and skills, processes and methods and emotional attitudes and values of three dimensions to get a better development, and strive to maximize the effectiveness of experimental teaching demonstration, emphasizing the demonstration experiments in innovative 
teaching content, methods of presentation. In short, under the background of new curriculum, demonstration experiment should be given adequate attention, students should pay more attention to scientific research ideas and methods, students develop the innovative thinking that demonstration experiment in physics teaching should be more extensive.

Usually teachers with teaching content and operations performed exemplary experiment are unique approach to teaching art teacher display. Through demonstration experiment, to study physical phenomena will clearly show in front of students, of the abstract to the concrete, vivid becomes boring to guide students to observe the experimental phenomena and thinking, stimulate their desire for knowledge. During the presentation, the teacher together with vivid taught so that students can more clearly understand the physical concepts and laws, thereby achieving a multiplier effect.

Physics demonstration experiment students observe, understand and master the textbook knowledge; students physical thinking ability and mastery of the scientific method; students awareness of innovation as well as to establish operations example, to stimulate student interest in learning, inspire students 'thinking, to improve students' scientific inquiry, and enhance students analyze and problem-solving ability aspect plays a greater role, and classroom teaching has an important supporting role.

\section{The Main Operating Environment of Computer Guidance System}

Computer Guidance System is a set of software tools for web design, dynamic web programming designed, based on system architecture .NET platform B / S (browser / server) mode. B / S model of software deployment system is easy to install, simple to use and easy maintenance, and other advantages of small burden. The operating system support Windows98, operating environment Windows2000, Windows XP's.

\section{The Main Module Structure, Interface, Layout and Function of Computer Guidance System}

Computer Guidance system mainly include physical knowledge of computer systems, is divided into six modules according to the classification physics course, there are the mechanical and thermal, optical, electromagnetic, and wave, modern and comprehensive physical and Wikipedia, classification clear. The six modules in the link on the main interface with a variety of content, functionality varies. System module structure six modules to add a hyperlink in any module, there is a corresponding picture, text, video, flash animation small.

Click mechanics and thermal science, a new screen will appear on the left part of the navigation menu, you can choose to go to the next page or on the page, return to the main interface, and so on; the body of the pilot project is to demonstrate the corresponding name and image equipment. For example: In the Mechanical and Thermal module including Bernoulli suspended ball, the aircraft lift, turntable conservation of angular momentum, gyroscopic precession instrument, moment of inertia and mass distribution. Optionally a pilot project click, it will enter the body, the body comprising: a phenomenon articles, articles principle, expand papers and background papers, which corresponds to the left part of the navigation menu for the phenomenon of papers, articles principle, expand papers and background papers. Each pilot project corresponds to experimental phenomena, principles, expand knowledge and theoretical background. Students can click on the name of the project to understand the principle of the phenomenon, the theoretical background and then a deeper understanding of the physics content. The content plays a different role in physics demonstration experiments and exploration area.

Phenomenon Articles. Computer playback software will demonstrate existing experimental demonstration out with music, text, the transient and difficult to distinguish or physical phenomena and laws of incomprehensible converted into an intuitive, clear, long-lasting physical or digital image signals, the abstract knowledge of physics simplified, figurative, vivid, help students deepen their understanding of physics theorems, laws, rules, and so understand and master, memory consolidation student demonstration experiment by watching the video, it will have its curious 
physical phenomenon, then stimulate interest in looking for answers, with questions continue to think and study. Effective Approaches to form a physical concept papers for students to understand the laws of physics have a guiding role is to train students to observe, thinking, creative ability, enhance their discovery, analysis and problem-solving skills

Principle Articles. Is the principle articles principle demonstration experiment experimental projects comprehensive overview, from different angles to elaborate experimental principle, there is a certain breadth and depth, unlike simple verification experiment in the classroom as in "more than 200 hours to digest each term demonstration experiment is impossible, the introduction of computer systems not only lead to guide students to learn effective learning, while reducing the frequency of teachers' work, keep things simple. principle chapter so that students demonstrate a more thorough understanding of the phenomenon and deeper memory, stimulate students' interest in learning university physics, and even attracted a group of students from this commitment to exploration and research in physics.

Expand Papers. Expand chapter is mainly based on physical phenomena will be the original theory of knowledge and real-life, modern science and technology associated with the knowledge of physics to explain. Through physical phenomena to the principles of the video presentation, to expand knowledge, to lead the development of the students with the eyes of exploration, innovation, linked to real life. As in the demonstration classroom, teachers for each demonstration experiment project preset several issues to enable students to think to answer. After the demonstration lesson, students should experiment on issues raised in the form of small paper summarizes, including issues they are interested in. After the phenomenon of papers, articles principle to expand the application papers listed first lightning rod in real life, and then asks questions "Violent force lightning ", and then contact the reality that" lightning can reach what temperature "," Lightning maintaining the ecological role in the Earth, "' lightning rod it is really foolproof "," information age communication tools how to effectively mine "tool can participate lightning war", and in front of these issues the Add button, then click the button It will link the relevant scientific knowledge content. Thus, expanding the chapter to help students understand the relationship between society and the physical phenomena of knowledge, the importance of physics in life; increased student motivation, motivate students to ascertain the unknown world, pioneering and innovative, bold and enterprising.

Background Papers. Background chapter is dedicated to describing the laws of physics, the laws of the historical background conditions arising, including in what conditions, what time, who will find out what the laws of the introduction of relevant scientists Biography, scientific achievements, anecdotes, so that students fully aware of the scientific achievements the hard-won experience of scientists from the great wisdom and spirit of exploration.

In the lightning rod demonstration project in Franklin leads to great masters, to enable students to understand his contribution to electromagnetism; describing acoustic phenomenon in the process of expanding the technology to eavesdrop, and dates back to ancient China's contribution to the study of acoustics, allow students to and from ancient times to this ancient repeated comparisons scrutiny, access to new progress; on a mirage, is the ancient Bo today, so that students consolidate the basis of existing knowledge, to deepen the knowledge.

Six modules are very close in structure to the content plays a different role in the physical presentation and exploration practice. Another example is a physical encyclopedia This module structure is rich in content, broad scope of knowledge and interesting. It includes the perspective of the history of physics, physics Grand Records, physics milestone in scientific discovery resume, Chinese ancient physics, text, video, etc. to show the scientific monument since ancient times in the history of physics. Many important laws of classical physics, the laws of the birth of the conditions of the times, scientific research and great experience and great achievements, military, space physics, life physics and fun physics on its lower historical links. Serious physical theory of abstract both interesting and full of life physically, so that students in the knowledge of the physical ocean travel. Why Life "fragrant meals, porous frozen tofu, crispy popcorn" These phenomena, the best way is to use physical theory to explain. From curiosity to perception, from interest to innovation, it 
is undoubtedly the best physics theory with practice and interpretation, but also cultivates students' innovative practices and ability to engage in scientific research.

\section{Application of Computer Guidance System in Physical Demonstration and Exploration}

In knowledge transfer and capacity building, train students' innovative quality education should be a key factor. Purpose of physics demonstration experiments and exploration is to make laboratory functions focus on informative and interesting for the physics teaching services, with emphasis on cultivating students' quality and ability to provide them with innovative soil and practice.

The establishment of a student to participate fully, exploratory, reflecting the physics demonstration experiment and explore new teaching pattern individualized learning, teaching process under the guidance of teachers become students in the study of the process of exploration, to guide college students actively participate in research activities. As a college, we are charged with the task of training qualified high school physics teachers, especially middle school teaching facilities located in remote areas of the southwest behind the lack of demonstration experiment equipment, and thus a lot of classroom demonstration experiment cannot be carried out. If we train graduates with a strong practical ability and instrument production skills, will undoubtedly play a positive role in promoting the development of local education.

In the "examination-oriented education" to "quality education" transition, how to use physics experiment guide students in scientific inquiry, cultivate students' innovative spirit and practical ability, not only is the question we must examine, as well as Teachers Students should consider and try problem. Microteaching having a dominant position of students, and timely feedback to improve the ability of fast and so is an effective Training for experimental teaching new skills and improve their methods of modern experimental teaching ability. Therefore, we conceive the physical presentation and middle school physics teaching, microteaching combine to allow students to get training and training from well-established.

\section{Conclusions}

Computer Guidance system covers the physical presentation and exploration practice in wide-ranging area, to show the diversity of forms, but also both interesting, since his student incentives to guide and improve the students' awareness of innovation, the development of students' creativity and scientific experiment ability, teachers, students consolidate the knowledge, improve self-effective resources.

\section{References}

[1] Xu Yang. The Era Education, Vol. 6 (2011) No 53, p.58-60

[2] Wang Yusheng. North China Water Institute (Social Edition), Vol. 12 (2010) No 17, p.20-22

[3] Hu Rong. China Electric Power Education, Vol. 17 (2010) No 20, p.60-63

[4] Wang Kuailiang. Fujian University (Natural Science), Vol. 29 (2008) No 27, p.21-23

[5] Dengbo Chang. Experimental Technology and Management, Vol. 8 (2003) No 27, p.57-60 